\title{
GB-SAR INTERFEROMETRY DISPLACEMENT MEASUREMENTS DURING DEWATERING IN CONSTRUCTION WORKS: THE CASE OF LA SAGRERA RAILWAY STATION IN BARCELONA, SPAIN.
}

\author{
A. Serrano-Juan, E. Vázquez-Suñè, O. Monserrat, M. Crosetto, C. Hoffmann, A. Ledesma, R. \\ Criollo, E. Pujades, V. Velasco, A. Garcia-Gil, M. Alcaraz
}

\begin{abstract}
Construction processes require monitoring to ensure safety and to control the new and existing structures. Traditional monitoring is based on land surveys and geotechnical instruments and only allows for point-like measurements. Ground-based Synthetic Aperture Radar (GB-SAR) is a remote sensing radar installed in the ground that offers the possibility of acquiring measurements in 2D covering areas of up to a few square kilometers in a single acquisition. Because the GB-SAR technology measures phase shifts along the line-of-sight, it only allows for measurements in the longitudinal direction. Moreover, this technology requires coherence between subsequent acquisitions. These restrictions can be a limitation to the usage of GB-SAR for monitoring a construction process because in this context, the movements of soil and existing structures occur in any direction and at a very fast pace. This paper aims to test the GBSAR suitability to measure movements during construction. To do so, an experiment was performed in the future railway station of La Sagrera, Barcelona (Spain), in which GB-SAR was used to accurately quantify wall displacements induced by dewatering and proved to be helpful to understand structural deformations and to identify vulnerable areas. The results were compared to traditional monitoring data and numerical models to confirm the reliability of the GB-SAR measurements.
\end{abstract}

\section{Highlights}

- $\quad$ GB-SAR is suitable to monitor deformation phenomena in soil and structures.

- $\quad$ GB-SAR precisely quantified wall displacements induced by dewatering.

- $\quad$ GB-SAR complements the traditional monitoring techniques.

- $\quad$ Traditional data and numerical models confirmed the GB-SAR measurements.

- $\quad$ GB-SAR can help to understand structure deformations and identify vulnerable areas.

\section{Keywords}

Ground-Based SAR, civil works, excavation, monitoring, dewatering 


\section{INTRODUCTION}

Civil projects can be especially challenging when construction is under the water table and in urban environments. The impacts on both aquifer and construction areas must be limited, requiring construction designs that ensure safety compliance and preservation of the aquifer conditions. As a result, it is necessary to adopt corrective measures previous to, during, and/or after the construction. In all cases, these measures must be supervised by monitoring the hydraulic heads, soil movement (heaves and subsidence), and movements of adjacent buildings (these being the most common controlled parameters).

Traditional infrastructure project monitoring is based on land surveys and geotechnical instruments. The most common topographic techniques include leveling, total stations, Differential Global Positioning System (DGPS), and robotic total stations, and the geotechnical techniques include pendulums, inclinometers, extensometers, piezometers, gyros, and optical fiber-based techniques (Dunnicliff, 1988; Marchamalo et al., 2011). Some of these techniques, such as DGPS, robotic total stations and optical fiber-based methods, allow for automatic measurements and continuous monitoring. Although all of these techniques are widely accepted and used, they are susceptible to the weather conditions (i.e., they are difficult to use during a storm) and still allow only point-like measurements, requiring interpolation and extrapolation to achieve a complete measurement understanding.

In the last few decades, new technologies for assessing soil movements have evolved rapidly. Remote sensing imaging systems, such as synthetic aperture radar (SAR), now offer the ability to capture complete deformation patterns (2D information) and the possibility of both day and night operation, independent of the weather conditions (storm, wind, rain, and sun). The SAR sensors can be installed in satellites or on the ground (GB-SAR). While satellite acquisitions cover areas of $100 \mathrm{~km}$ by $100 \mathrm{~km}$ at longer time periods, ranging from days to weeks (depending on the satellite), ground-based systems allow for continuous monitoring in smaller areas (usually approximately 1-2 $\mathrm{km}^{2}$ ) and shorter revising times on the order of minutes. GBSAR presents some limitations, such as the necessity of measuring displacements perpendicular to the Line-Of-Sight (LOS) and the requirement for pixel coherence over time. Nevertheless, the GB-SAR system provides more capabilities compared with other deformation measurement techniques due to its high sensitivity to small deformations, its long-range measurement capability (up to several kilometers) and its simultaneous measurement of a vast number of points.

GB-SAR has been successfully used, tested and accepted in a variety of applications. The most common applications include the monitoring of slope instability related to rockslides (Tarchi et al., 2005), landslides (Tarchi et al., 2003; Schulz et al., 2012), or volcanoes (Casagli et al. 
2010). Other important GB-SAR applications are urban infrastructure and building monitoring (Pieraccini et al., 2004; Tarchi et al., 1997; Tapete et al., 2013), dam monitoring (Tarchi et al., 1999), dike monitoring (Takahashi et al., 2013) and glacial motion monitoring (Luzi et al., 2007). A general review of the GB-SAR technology is provided by Monserrat et al. (2014).

Due to the characteristics of GB-SAR, a very large variety of displacements can be accurately measured. However, GB-SAR has not yet been applied as a monitoring tool during infrastructure projects. This might be due to the difficulty of properly locating the sensor or to the lack of elements that remain coherent over time. Fortunately, these drawbacks can be overcome by combining the GB-SAR with traditional displacement measurements and by analyzing which structures are most vulnerable and should be monitored.

This paper aims to demonstrate how to use GB-SAR to continuously monitor infrastructure projects in time and space. To demonstrate the utility of applying GB-SAR to structure monitoring, an experiment was conducted in the future railway station of La Sagrera, Barcelona (Spain). This experiment consists of the design, implementation, quantification and interpretation of a pumping test that allows the GB-SAR to measure the movements of a structure during the construction phase. Based on the geological, geotechnical, hydrogeological and construction knowledge of the work, the structures susceptible to movement in the next phase of the project were selected. The results of GB-SAR are compared with conventional monitoring measures.

\section{PROBLEM STATEMENT AND GB-SAR EXPERIMENT DESIGN}

\subsection{GB-SAR BASICS}

This section briefly reviews the most important characteristics of GB-SAR deformation monitoring. The GB-SAR is an imaging sensor based on the synthetic aperture radar (SAR) technique (Fortuny and Sieber, 1994). For each image pixel, a GB-SAR provides a complex number, which consists of the In-phase and Quadrature components of the received echo, from which the signal phase and amplitude can be derived. The amplitude is related to the power of the reflection of the observed scene, while the phase contains geometric information, which is related to the distance between the radar antenna and the given target. The main GB-SAR observation is given by the interferometric phase, which is obtained using the phase difference of images acquired at different times. The interferometric phase is directly related to the displacements of the observed scene in the time elapsed between two acquisitions, providing the displacements of individual image pixels. The displacement associated with a given pixel represents a weighted average of the displacement of all of the elements included in the pixel footprint. The weight is given by the amplitude of the response of each single element. 
The main steps of GB-SAR data processing include the following: (i) acquisition of a stack of GB-SAR images; (ii) image co-registration; (iii) selection of the coherent pixels (the pixels maintain their relative position and phase, and it does not affect the degree of correlation between two images), i.e., the pixels that can be exploited for deformation monitoring; (iv) phase unwrapping; (v) phase integration, estimation and removal of the atmospheric phase component; (vi) estimation of the LOS deformation time series for each coherent pixel; (vii) computation of the three coordinates (e.g., East, North, and height) of each measured pixel; and (viii) (optional) transformation of the LOS deformation in the actual deformation direction (this can only be performed if the deformation direction is known).

The main shortcomings of GB-SAR deformation monitoring are as follows: (1) the pixel response must be coherent over time (i.e., between different image acquisitions); (2) the reconstruction of the interferometric phase (unwrapping phase (Ghiglia and Pritt, 1998)) is error-prone, especially for discontinuous GB-SAR measurements; and (3) the sensor measures displacement along the radar Line-of-Sight (LOS), and therefore, displacements oblique to the LOS can be computed while displacements perpendicular to the LOS cannot be measured.

However, GB-SAR deformation monitoring presents many advantages. (1) The deformation monitoring process can be highly automated, independent of the weather conditions and the day-night cycle. (2) GB-SAR is able to monitor deformation phenomena, from a few millimeters per year up to $1 \mathrm{~m}$ per $\mathrm{h}$, at distances of up to several kilometers (the precision ranges from sub-millimeters to a few millimeters, depending on the target characteristics, the sensor to target distance and the distance from the reference point). (3) A GB-SAR measurement can cover an area of $1-2 \mathrm{~km}^{2}$, providing a dense measurement coverage of the observed scene (the GB-SAR instrument used in this study ranges from approximately four measurements $/ \mathrm{m}^{2}$ at $100 \mathrm{~m}$ to 0.4 measurements $/ \mathrm{m}^{2}$ at $1000 \mathrm{~m}$ ). Finally, (4) GB-SAR can be used in two acquisition modes: continuous (the instrument is left installed in situ, acquiring data on a regular basis, e.g., every few minutes) and discontinuous (the instrument revisits a given site periodically, e.g., weekly or monthly) (Crosetto et al., 2014).

\subsection{LA SAGRERA STATION EXCAVATION AREA}

\subsubsection{General situation}

La Sagrera railway station (Figure 1) is located in the metropolitan area of Barcelona (Spain) and aims to become the city's major intermodal transit hub. The station is expected to receive more than 100 million passengers per year, combining high-speed trains, short- and mediumdistance trains, four metro lines and buses (ADIF, 2015). The railway station construction began in 2010 and is planned to be completed by 2020. At the time of the experiment (February 2014), 
all diaphragm walls were built (finished in February 2013), the dewatering system was drilled and equipped (finished in November 2012), and the site leveling was completed (no excavation yet).

\subsubsection{Geological and hydrogeological settings}

The metropolitan area of Barcelona is located on the Mediterranean coast of NE Spain. Geologically, this area is formed by a coastal plain (the Barcelona coastal plain) bounded by two Quaternary deltaic formations (corresponding to the Besòs and Llobregat rivers) and an elevated area, the Catalan Coastal Ranges (mainly Paleozoic rocks composed of granodiorite materials) (Sanz, 1988). More concretely, the study site is located in the actual plain, which consists of Quaternary formations that overlie a substrate mainly formed by Paleozoic and Pliocene series. The Quaternary formation presents a very heterogeneous pattern and can be divided into the Lower Quaternary (Pleistocene) and Upper Quaternary (Holocene). The Pleistocene is made up of several cycles composed of alluvial sequences. The upper Quaternary is mainly composed of torrential, alluvial and foothill deposits, where gravels and sands with a high proportion of clay matrix are present. All of these quaternary deposits are $30 \mathrm{~m}$ thick. The pre-Quaternary substrate consists of the Pliocene series, mainly composed of marine blue marls and sandy marls and Paleozoic granite. The entire study area is cut by many fractures that compartmentalize the pre-Quaternary substrate; specifically, the construction area is crossed by a fracture (oriented NNW-SSE) that separates the two Pliocene series: Pliocene marls (south) and Pliocene sandy marls (north).

Hydrogeologically, the Quaternary and pre-Quaternary materials can be regarded as a layered aquifer with high vertical heterogeneity, with an effective transmissivity of $100-200 \mathrm{~m}^{2} / \mathrm{d}$. The hydraulic conductivity (k) of the Quaternary clay layers (low-permeability layers) ranges from 0.001 to $0.01 \mathrm{~m} / \mathrm{d}$, the $\mathrm{k}$ of the Quaternary sand and gravel layers (high-permeability layers) ranges from 0.1 to $10 \mathrm{~m} / \mathrm{d}$, the $\mathrm{k}$ of the Pliocene fine materials (marls) ranges from 0.001 to 0.01 $\mathrm{m} / \mathrm{d}$, and the $\mathrm{k}$ of the sands ranges from 0.1 to $10 \mathrm{~m} / \mathrm{d}$. These values were derived from the numerous hydraulic tests performed in the study area and from numerical models developed for calibration purposes.

The water table oscillations during the $20^{\text {th }}$ century, due to extensive water extractions at the beginning of the century (drawdowns of approximately 10-15 m) and the water table recovery after the 1970s (Vázquez-Suñé et al., 2005), resulted in an over-consolidation of the soil, changing the soil deformation from plastic to elastic (Odometric curve). This behavior has been appreciated in the nearby High Velocity Railway shafts of Padilla (approximately 1,500 m) and Trinxant (approximately 500 m) in Barcelona, Spain (Pujades et al., 2014a, 2014b). Basic soil parameters were obtained from laboratory and field tests (see Table 1). The cohesion ranges 
from 0 to $70 \mathrm{kPa}$, the soil unit weight ranges from 20 to $21.5 \mathrm{kN} / \mathrm{m}^{3}$, the friction angle is in the range of $26^{\circ}$ to $38^{\circ}$, and Poisson's ratio is between 0.3 and 0.4 .

Figure 2 summarizes the hydrogeological and geological characteristics of the study area. Figure 3 shows a detailed view of the excavation and the rail retaining wall (west).

\subsubsection{Construction characteristics}

The Sagrera station will occupy an area of approximately $70.000 \mathrm{~m}^{2}$ and requires a 20-m-deep excavation. The initial soil elevation is between +14 and +16 m.a.s.l. (meters above sea level), and the water table's natural position is between +2 and +4 m.a.s.l. The dewatering process is performed inside diaphragm walls (the bottoms of which are at -20 m.a.s.l.) to meet the structural requirements and to reduce the water extraction and subsidence outside. The diaphragm walls are anchored on their upward sides to support the railway lines (which have been deviated and are active during the entire process). The excavation bottom is at -8 m.a.s.l., requiring a water table drawdown of approximately $12 \mathrm{~m}$. The first excavation phase involves extraction of the non-saturated soil (the bottom of which is at +2 m.a.s.l.). The second phase excavates the saturated soil, from +2 m.a.s.l. to -8 m.a.s.l. There are 26 wells (which reach down to -20 m.a.s.l.) and a network of 48 piezometers (20 inside and 28 outside of the excavation area) with different depths and screens to execute and control the dewatering process.

The construction stages are (i) design, (ii) diversion (any services on the site such as drainage, water and gas piped services, power and communication cables and traffic must be diverted before the construction starts); (iii) site clearing; (iv) diaphragm wall construction and nonsaturated soil excavation; (v) dewatering and excavation; (vi) building construction; and (vii) building operation. At the time of this experiment (February 2014), all diaphragm walls were built and the dewatering system was ready (construction stage iv was finished).

See Figure 1 for the site study area and the construction details. Figure 2 shows a cross section at the moment of maximum excavation, and Figure 3 shows a detailed view at the time of the experiment.

\subsection{EXPERIMENT SETUP}

The current stage of construction presents a great opportunity to measure structural displacements. The experiment involves the following steps. (1) A pumping test is used to generate a controlled deformation: drawdowns in a pre-consolidated soil result in an elastic soil deformation behavior. (2) Numerical methods are used to design the pumping test (hydrogeological models) and to anticipate the soil and wall displacements (hydromechanical models). (3) GB-SAR measurements are spatially and temporally correlated with 
hydrogeological data (such as pumping rates and piezometric level evolutions) to evaluate the deformation produced by the dewatering. (4) GB-SAR measurements are compared with direct observations and other conventional displacement measurement techniques (such as total station measurements, inclinometers and extensometers). (5) Numerical models are calibrated with the real displacement and hydrogeological measures, and the results are compared with the GBSAR measurements.

\subsubsection{Pumping test}

A 3-week pumping test was performed using eight pumping wells. Each pump extracted approximately $4 \mathrm{~L} / \mathrm{s}$, rising to $32 \mathrm{~L} / \mathrm{s}$ when all eight pumps were extracting. Instead of starting the eight pumps simultaneously, the pumps were started sequentially (from the southern to the northern edge) to generate eight hydraulic steps. Every hydraulic step (when a pump starts) increased the water extraction, decreased the piezometric level and increased the soil deformation. The main advantages of this pumping test design rely on (1) the non-homogenous temporal and spatial deformation generation (which produces a complex deformation); (2) the limit of detection identification for every measurement technique; (3) the construction defects detection (i.e., open joints in the diaphragm walls - Vilarrasa et al., 2011, Pujades et al., 2012); (4) the numerical modeling calibration and validation; and (5) the dewatering system status inspection. The maximum drawdown was $8 \mathrm{~m}$, increasing inside the pumping wells according to the head loss.

Figure 1 shows the position of all of the pumping wells, distinguishing those activated in this pumping test in yellow, numbered in the order of activation.

\subsubsection{GB-SAR location}

The position of the radar is a fundamental aspect as the sensor performs LOS measurements. In construction projects, where the imaged scene can vary considerably over time, the GB-SAR can only be used to monitor those elements, buildings and structures that remain coherent over time. To measure all of the horizontal (structures) and vertical (soil) displacements, the GBSAR sensor must be located at sufficient height and distance to have a LOS inclination as close as possible to $45^{\circ}$. The geometry of the study site allowed us to obtain a low LOS elevation (ranging from $2^{\circ}$ to $8^{\circ}$ ). This quasi-horizontal LOS resulted in a good sensitivity to horizontal displacements and limited sensitivity to vertical displacements. The radar was located perpendicular to the northern diaphragm wall and was able to measure approximately two-thirds of the construction area. Figure 4 shows the radar location and the field of view. 
The radar measurements were performed using a Ku-band interferometer, IBIS-L, manufactured by IDS Spa. IBIS-L uses a radar wavelength of $1.74 \mathrm{~cm}$. The measurements were taken using a range resolution of $0.5 \mathrm{~m}$ and an azimuth resolution of $4.4 \mathrm{mrad}$ (which, for example, corresponds to 0.44 and $0.88 \mathrm{~m}$ at 100 and $200 \mathrm{~m}$, respectively). Additional information related to the sensor is provided in Bernardini et al. (2007), IDS (2013), Monserrat et al. (2014) and the IDS web page (www.idscorporation.com). The SAR images were acquired over a time period of $5 \mathrm{~min}$. For each measured point, the displacements were estimated corresponding to the date of each acquired SAR image. The GBSAR data processing followed the steps listed in Section 2.1. In particular, the phase unwrapping was based on the Minimum Cost Flow algorithm (Costantini, 1998), and the estimation and removal of the atmospheric phase component were based on stable areas that surround the deformation area of interest.

\subsubsection{Other measurements}

The soil and diaphragm wall displacements were monitored by a system composed of extensometers, inclinometers and topographic targets located inside and outside of the enclosure. In the zone of interest, the subsidence in the excavation area was measured by four incremental extensometers, and the wall displacements were controlled by 10 inclinometers and 10 topographic targets. The total station was a TCRP 1202 R100 Leica model and measured both the soil subsidence inside the enclosure (using manual target-prism) and the topographic targets on the wall. The periodicity of the measurements ranged from days to months, depending on the progress of the construction project. During the experiment, measurements were expected to be taken at least three times: previous to, during (at the maximum pumping rate) and after the pumping test. Figure 4 shows the location of all of the extensometers, inclinometers and topographic dartboards at the experiment site.

\subsubsection{Hydrogeological and hydromechanical numerical models}

Numerical models are necessary to simulate and understand the mechanisms that control the structural movements: for the design of the pumping test (hydrogeological models) and for prediction of the soil and wall displacements (hydromechanical models).

The finite element code TRANSIN-IV (Medina et al., 2000; Medina and Carrera, 2003) is used with the visual interface of VISUAL TRANSIN (UPC, 2003) to build the hydrogeological model. A 3D model is constructed and divided into 17 layers. This distribution enables us to represent the station accurately in its real depth. Borehole and piezometer screens are located in their corresponding layers. 
The finite element model, based on the CPLAXIS commercial code, is used to establish the hydromechanical model. This model simplifies the shape of the excavation to a rectangle of $500-\mathrm{m}$ length and $80-\mathrm{m}$ width and cuts the rectangle into a series of 2D transverse sections, defined at distances of approximately $35 \mathrm{~m}$, which require 35 sections to simulate the entire diaphragm wall (sections 6 to 23 are measured using the GB-SAR during the experiment). Every section contains the structural elements of the retaining structure (cast-in-place diaphragm walls and anchors). Additional configurations are set up in some sections when special features (geometric, structural, or geotechnical) required them. The Hardening Soil Model within the (CPLAXIS code is selected as a mechanical constitutive law, as was shown to be convenient for simulating the behavior of the Quaternary and Tertiary soils in Barcelona (Pujades et al., 2014b). Figure 3 shows a detailed soil and excavation profile of the hydromechanical numerical model corresponding to the transverse section A6 over the period of the experiment.

\section{RESULTS AND DISCUSSION}

The experiment was performed from January $28^{\text {th }}$ to February $18^{\text {th }}, 2014$. The pumping test lasted three weeks: two weeks of pumping (from January $28^{\text {th }}$ to February $10^{\text {th }}, 2014$ ) and another week to observe the drawdown recovery. Four pumps were activated during the first week (daily, from Monday to Thursday), and the rest were activated during the second week. Water pressure data were collected manually (five times per day) and automatically (every 5 min) from 29 points; four dartboards were measured previous to, during, and after the experiment; over 33,000 coherent points were collected every 5 min by the GB-SAR radar. In this analysis, only the night GB-SAR data are used for two main reasons: (1) to reduce the effect of the traffic in the construction area and increase the number of coherent points and (2) to reduce atmospheric effects (such as changes in humidity or temperature) in the measured SAR data. Multiple interferograms were processed to check the consistency of the phase unwrapping.

Two displacement maps (Figure 5) compare the original soil and wall positions at the maximum drawdown time step (Figure 5.2) and after the drawdown recovery (Figure 5.3). In Figure 5, the LOS displacements are color-coded. The black colored pixels represent pixels with no coherence. When the water pressure is reduced inside the enclosure during the pumping test, the water pressure out of the enclosure pushes the wall toward the interior of the enclosure (in this case, toward the radar) and produces a deformation of the wall (see Figure 5.2). When the dewatering ceases, the water pressure increases inside the enclosure, pushing the wall in front of the sensor and restoring the original wall position. The accumulated displacements are shown in Figure 5.3. An intermediate interferogram (from the maximum deformation up to the end of the experiment) is very similar to the map shown in Figure 5.2 but with opposite displacement 
values. In this figure, one may observe that the wall connection to the railway lines on its upward side results in a very rigid structure (the wall and the railway) that moves together. Eight sections (A1 to A8) were analyzed to determine the sensitivity of the wall to the drawdown: they undergo maximum horizontal displacements that range between 2.7 and 3.7 $\mathrm{mm}$ (see Figure 6). The negative values demonstrate that the wall was moving closer to the radar sensor (the LOS distance is decreasing). The displacement distribution along the wall was not constant (see Figure 6.2); this is logical because both anchors in the diaphragm walls and the drawdowns induced by the progressive pumping test were not constant either (see Figures 6.1 and 6.3). The GB-SAR radar position was not high enough, and only a quasi-horizontal LOS was achieved (see the bottom parts of Figures 5.2 and 5.3). The soil displacement results were discarded due to the weak radar sensitivity to vertical displacements and the lack of coherence inside the diaphragm walls.

A spatial-temporal correlation analysis between the measured GB-SAR displacements and hydrogeological parameters was conducted. Pumping rate evolutions, piezometric level time series and wall displacements were correlated in Figure 7. The graph shows a strong cause-andeffect relationship over time among all of the variables. The pumping and piezometric level recovery periods coincide with the displacement trends: the distance to the radar sensor was reduced when pumping, and the original distance was recovered after the pumping stopped.

Water levels of -4 m.a.s.l. (occasionally below that inside the pumping wells, due to head losses) were measured during the experiment. From a hydromechanical point of view, the soil responds with an elastic behavior, with very little variation during the pre-pumping, postpumping and recovery cycle (Figure 5 and Figure 7). However, due to a power outage, the GBSAR system stopped acquiring data during the drawdown recovery (represented as a dashed line in Figure 7); therefore, it was not possible to obtain the measurement of the exact wall response when the pumping ceased. This measurement was only possible at the end of the campaign (when we were able to make the last measurements). In principle, this last measurement could contain unwrapping errors, but they would be multiples of 2p, i.e., multiples of 1.74/2 cm in terms of displacements. We consider such displacements rather improbable.

The northern side of the diaphragm wall was completely measured before, during, and after the experiment, and the rest of the wall was partially measured. Inclinometers installed in the diaphragm wall were not read during the pumping test. Despite the few available data points and the small displacements (very close to the limit of detection), the GB-SAR measurements (right side edge) and the manual measurement of target MON4 (measurement with total station) obtained coincident values: MON4 measured $3.12 \mathrm{~mm}$, and A8 measured $3.16 \mathrm{~mm}$. The rest of the acquired manual data were used to validate the hydromechanical model. 
Finally, a hydromechanical model was used to check whether the displacement distribution was similar along the wall and of the same order of magnitude. Wall displacements induced by dewatering inside the excavation were calculated for different sections. The ground level was assumed to be at +3.00 , which corresponds to the reported level at the time of the test. The ground water level inside the excavation varied, depending on the section and based on the levels measured during the pumping test. An example of a calculated horizontal displacement section is shown in Figure 6.1 (section A6). The use of anchors in the upper part of the wall decreases the head displacements, producing an arched deformation shape, locating the maximum movement at approximately 6 m.a.s.l. The shape of this arch varies in each section, depending on the distribution of the anchors and the foot wall depth.

The computed and measured horizontal displacements for the western retaining wall are shown in Figure 6.2. Horizontal displacements computed at the top of the wall and at ground level are presented in all sections. The results show that the measured displacements are in the range of 3 $\mathrm{mm}$, which is in good agreement with the lower range of the computed values (approximately 4 $\mathrm{mm}$ ). Considering that no particular adjustment of the model was made and that only groundwater levels were locally adjusted, the calculated results validate the measured displacements: the measured and predicted results appear to be in very good agreement, and only local discrepancies are observed. These discrepancies can be explained by changes in geometry and anchor distribution. In some sections, the complex vertical deformation shape obtained in the CPLAXIS model (Figure 6.1) corresponds to a single point measured by means of GB-SAR, which makes the comparison difficult.

\section{CONCLUSIONS}

The experiment conducted in the La Sagrera railway station showed that GB-SAR can measure movements during the construction stage. GB-SAR has precisely quantified the horizontal wall displacements induced by dewatering. Manual data and numerical models have confirmed the measurements with a correlation analysis and by comparing measurements and deformation patterns, which produced similar results. Knowledge of the geology, hydrogeology, geotechnics and construction processes was found to be fundamental to design, perform and interpret the experiment. The results of this experiment are satisfactory. However, more detailed data obtained from the total station, extensometers and inclinometers would improve the reliability of the GB-SAR measurements. Moreover, the addition of an alert system to the GB-SAR sensor would ensure the continuous acquisition of the data.

From this study, the following conclusions were drawn. First, the sensor location represents a critical aspect because, in construction projects, the imaged scene can vary considerably over time, and GB-SAR can measure only those elements, buildings and structures that remain coherent over the observed period. Second, due to the high sensitivity to small displacements, 
the coverage of large areas, and the dense quantity of measurements over the observed scene, the GB-SAR can be helpful in understanding the mechanisms that control structure deformations and to identify vulnerable areas. For example, the La Sagrera case study showed different wall displacements, depending on the position of the anchors and a strong connection between the wall and the railroad tracks. Finally, the GB-SAR automation allows for obtaining high density temporal coverage. Depending on the expected deformation response, the radar data acquisition can be automatically realized every few minutes (as in the case of La Sagrera), hours, or days.

\section{ACKNOWLEDGEMENTS}

The authors acknowledge ADIF (Administration), INECO (Construction Management), AudingIntraesa-Ayesa-Cicsa (technical assistance) and Dragados-Acciona-Comsa-Acsa (construction companies) for their support throughout the hydrogeological monitoring of the civil works. The authors were appointed by ADIF as external advisors during the construction of the station. Additional funding was provided by the Generalitat de Catalunya (Grup Consolidat de Recerca: Grup d'Hidrologia Subterrània, 2009-SGR-1057). E. Pujades gratefully acknowledges the financial support from the University of Liège and the EU through the Marie Curie BeIPD-COFUND postdoctoral fellowship (2014-2016).

\section{REFERENCES}

Administrador de Infraestructuras Ferroviarias (ADIF), 2015. Barcelona Sagrera Alta Velocitat. 2015.

Bernardini, G., Ricci, P., Coppi, F., 2007. A ground based microwave interferometer with imaging capabilities for remote measurements of displacements. In: Proc. GALAHAD Workshop Within the 7th Geomatic Week and the 3rd International Geotelematics Fair (GlobalGeo), Barcelona (Spain), 20-23 February.

Casagli, N., Catani, F., Del Ventisette, C., Luzi, G., 2010. Monitoring, prediction, and early warning using ground-based radar interferometry. Landslides 7 (3), 291-301.

Costantini, M., 1998. A novel phase unwrapping method based on network programming. IEEE Trans. Geosci. Remote Sens. 36 (3), 813-821.

Crosetto, M., Monserrat, O., Luzi, G., Cuevas-González, M. and Devanthéry, N., 2014. Discontinuous GBSAR deformation monitoring. ISPRS Journal of Photogrammetry and Remote Sensing, 93, pp.136-141.

Dunnicliff, J., 1993. Geotechnical instrumentation for monitoring field performance. John Wiley \& Sons. 
Fortuny, J., Sieber, A.J., 1994. Fast algorithm for a near field synthetic aperture radar processor. IEEE Trans. Antennas Propagation 41, 1458-1460.

Ghiglia, D.C., Pritt, M.D., 1998. Two-dimensional phase unwrapping: theory, algorithms, and software. Ed. Wiley, New York (USA).

IDS. 2013. IBIS Guardian Software v. 02.00 - User Manual. IDS Ingegneria Dei Sistemi S.p.A., Pisa, Italy.

Luzi, G., Pieraccini, M., Mecatti, D., Noferini, L., Macaluso, G., Tamburini, A., Atzeni, C., 2007. Monitoring of an alpine glacier by means of ground-based SAR interferometry. IEEE Geosci. Remote Sens. Lett. 4 (3), 495-499.

Marchamalo, M., Galán, D., Sánchez, J.A. and Martínez, R., 2011. La tecnología DGPS en la construcción: control de movimientos en grandes estructuras. Informes de la Construcción, 63(522), pp.93-102. doi:10.3989/ic.10.008

Medina, A., Alcolea, A., Carrera, J., Castro, L.F., 2000. Modelos de flujo y transporte en la geosfera: Código TRANSIN IV. [Flow and transport modelling in the geosphere: The code TRANSIN IV]. IV Jornadas de Investigación y Desarrollo Tecnológico de Gestión de Residuos Redioactivos de ENRESA. Technical publication 9/2000: 195-200.

Medina A, Carrera J, 2003. Geostatistical inversion of coupled problems: dealing with computational burden and different types of data. Journal of Hydrology, 281 (4), 251-264.

Monserrat, O., Crosetto, M. and Luzi, G., 2014. A review of ground-based SAR interferometry for deformation measurement. ISPRS Journal of Photogrammetry and Remote Sensing, 93, pp.40-48.

Pieraccini, M., Luzi, G., Mecatti, D., Fratini, M., Noferini, L., Carissimi, L., Franchioni, G., Atzeni, C., 2004. Remote sensing of building structural displacements using a microwave interferometer with imaging capability. Non Destruct. Test. Eval. 37 (7), 545-550.

Pujades, E., Carrera, J., Vázquez-Suñé, E., Jurado, A., Vilarrasa, V. and Mascuñano-Salvador, E., 2012. Hydraulic characterization of diaphragm walls for cut and cover tunnelling. Engineering Geology, 125, pp.1-10. doi:10.1016/j.enggeo.2011.10.012

Pujades, E., Vàzquez-Suñé, E., Carrera, J. and Jurado, A., 2014a. Dewatering of a deep excavation undertaken in a layered soil. Engineering Geology, 178, pp.15-27. doi:10.1016/j.enggeo.2014.06.007

Pujades, E., Vázquez-Suñé, E., Carrera, J., Vilarrasa, V., De Simone, S., Jurado, A., Ledesma, A., Ramos, G. and Lloret, A., 2014b. Deep enclosures versus pumping to reduce settlements during shaft excavations. Engineering Geology, 169, pp.100-111. doi:10.1016/j.enggeo.2013.11.017

Sanz, P. (1988) .El pla de Barcelona: Constitucio i caracteristiques fisiques (Coneguem Catalunya) (Catalan Edition). 
Schulz, W.H., Coe, J.A., Shurtleff, B.L., Panosky, J., Farina, P., Ricci, P.P., Barsacchi, G., 2012. Kinematics of the Slumgullion landslide revealed by ground-based InSAR surveys. In: Proc. Landslides and Engineered Slopes: Protecting Society through Improved Understanding - the 11th International and 2nd North American Symposium on Landslides and Engineered Slopes, Banff (Canada), 3-8 June, pp. 1273-1279.

Takahashi, K., Matsumoto, M., Sato, M., 2013. Continuous observation of naturaldisaster-affected areas using ground-based SAR interferometry. IEEE J. Sel. Top. Appl. Earth Observations Remote Sens. 6 (3), 1286-1294.

Tapete, D., Casagli, N., Luzi, G., Fanti, R., Gigli, G., Leva, D., 2013. Integrating radar and laser-based remote sensing techniques for monitoring structural deformation of archaeological monuments. J. Archaeol. Sci. 40 (1), 176-189.

Tarchi, D., Ohlmer, E., Sieber, A.J., 1997. Monitoring of structural changes by radar interferometry. J. Res. Nondestruct. Eval. 9 (4), 213-225.

Tarchi, D., Rudolf, H., Luzi, G., Chiarantini, L., Coppo, P., Sieber, A.J., 1999. SAR interferometry for structural changes detection: a demonstration test on a dam. In: Proc. IGARSS 1999, Hamburg, Germany, pp. 1522-1524.

Tarchi, D., Casagli, N., Fanti, R., Leva, D., Luzi, G., Pasuto, A., Pieraccini, M., Silvano, S., 2003. Landslide monitoring by using ground-based SAR interferometry: an example of application. Eng. Geol. $68(1-2), 15-30$.

Tarchi, D., Antonello, G., Casagli, N., Farina, P., Fortuny-Guasch, J., Guerri, L., Leva, D., 2005. On the use of ground-based SAR interferometry for slope failure early warning: the Cortenova rock slide (Italy). In: In Landslides: Risk Analysis and Sustainable Disaster Management. Ed. Springer, Berlin Heidelberg, pp. 337-342.

UPC (2003). Codigo Visual Transin 1.1 R65. Developed in the Department of Geotechnical Engineering and Geosciences (ETCG), UPC.

Vázquez-Suñe, E., Sánchez-Vila, X., Carrera, J., 2005. Introductory review of specific factors influencing urban groundwater, an emerging branch of hydrogeology, with referente to Barcelona, Spain.

Hydrogeology Journal. 13, 522-533.

Vilarrasa, V., Carrera, J., Jurado, A., Pujades, E. and Vázquez-Suné, E., 2011. A methodology for characterizing the hydraulic effectiveness of an annular low-permeability barrier. Engineering Geology, 120(1), pp.68-80. doi:10.1016/j.enggeo.2011.04.005 


\section{APPENDIX A. GB-SAR, MANUAL DATA AND HYDROMECHANICAL MODEL} RESULTS FOR ALL CROSS-SECTIONS.

\section{FIGURE CAPTIONS}

Figure 1. Geographical location of the study site. The yellow wells are the ones activated during the pumping test.

Figure 2. Detailed geological profile of the site. (1) Plan view of the geological basement, (2) Cross section A-B, (3) Cross section C-D. Excavation area, limited by diaphragm walls, is shown in light brown color. Both cross sections show the maximum excavation and the required dewatering system.

Figure 3. Soil and excavation profile corresponding to the transverse section A6 (see Figure 4 to locate the section) at the time of the experiment. A6 is also the transverse section of the hydromechanical model @PLAXIS.

Figure 4. Radar position, GB-SAR analysis area, manual acquisition data targets (blue circles, MON) and inclinometers (yellow squares), pumping well positions (red circles) and GB-SAR (black dashed lines) and @PLAXIS (pink dashed line) section analysis.

Figure 5. Radar output: displacements estimated by the GB-SAR. All pixels with discarded data due to the lack of coherence are shown in black. The red dashed line represents the measured diaphragm wall. Negative values represent movements towards the sensor.

Figure 6. Hydromechanical model (CPLAXIS) results. (1) Cross section: horizontal displacement induced by dewatering calculated in the model for section A6. (2) Plan view: computed (gray band) and measured (red arrows) horizontal displacements for the mountain side retaining wall in all sections considered. (3) Cross section: locations of the anchors.

Figure 7. Multi-parameter correlation: pumping rates, drawdowns and GB-SAR wall horizontal displacements. The measurements are shown in circles. The dashed line represents a data gap. The rest of the cross-sections are included in Appendix A.

Figure A1. GB-SAR, traditional monitoring data and hydromechanical model results for all cross-sections.

Table 1. Parameters of the Hardening Soil Model used in the CPLAXIS hydromechanical model. $\gamma \mathrm{t}$ is the soil unit weight, $\mathrm{c}^{\prime}$ is cohesion, $\phi^{\prime}$ is the friction angle, $\mathrm{E}$ is the Young's modulus, $v$ is Poisson's ratio, $\mathrm{m}$ is the power for stress-level dependency of the stiffness, $\mathrm{E}_{50}{ }^{\text {ref }}$ 
506 is the reference Young's modulus at $50 \%$ of the strength, $\mathrm{E}_{\mathrm{oed}}{ }^{\text {ref }}$ is the reference odometric 507 modulus, and $\mathrm{E}_{\mathrm{ur}}{ }^{\text {ref }}$ is the reference unloading-reloading modulus. 


\section{- Figure 1.}

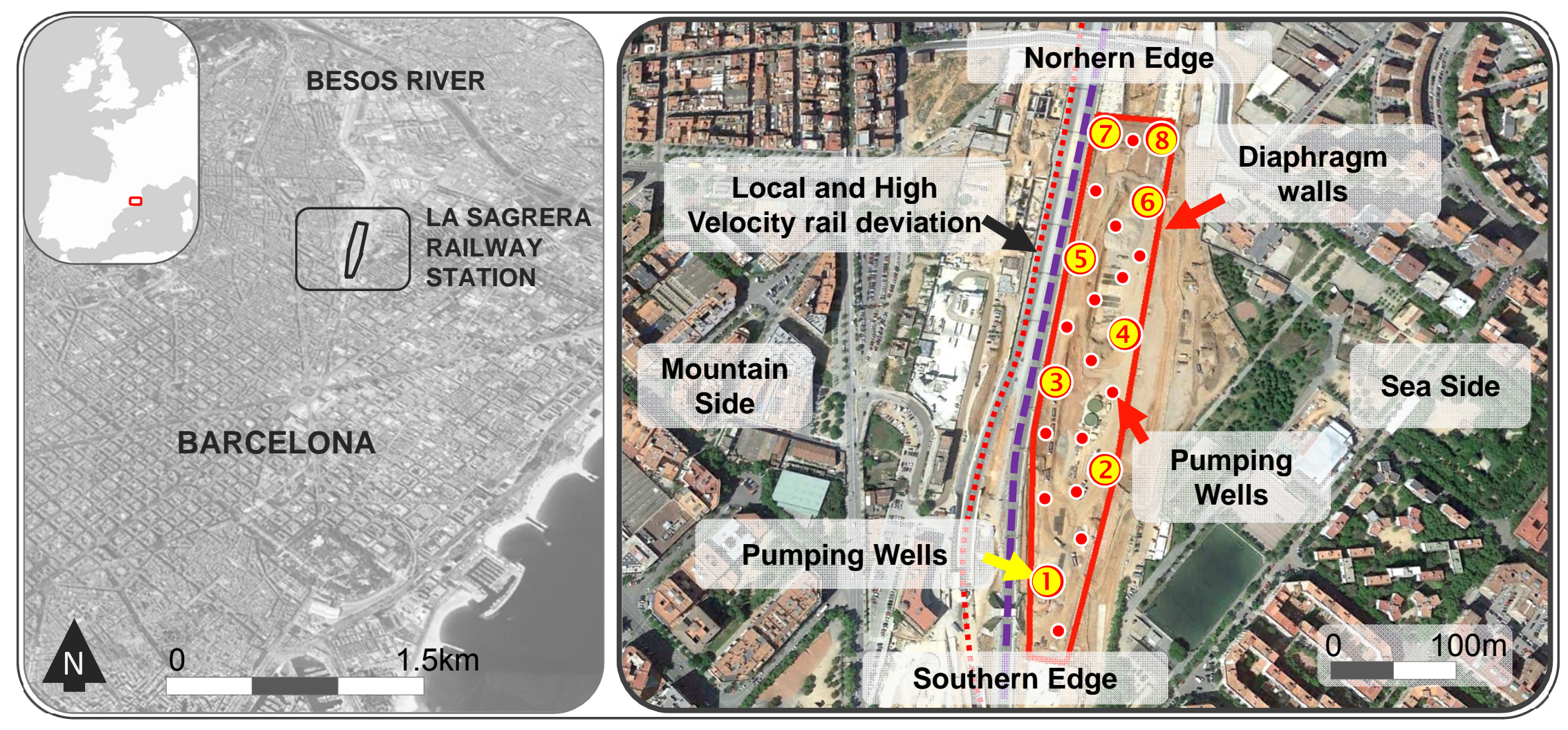




\section{- Figure 2.}
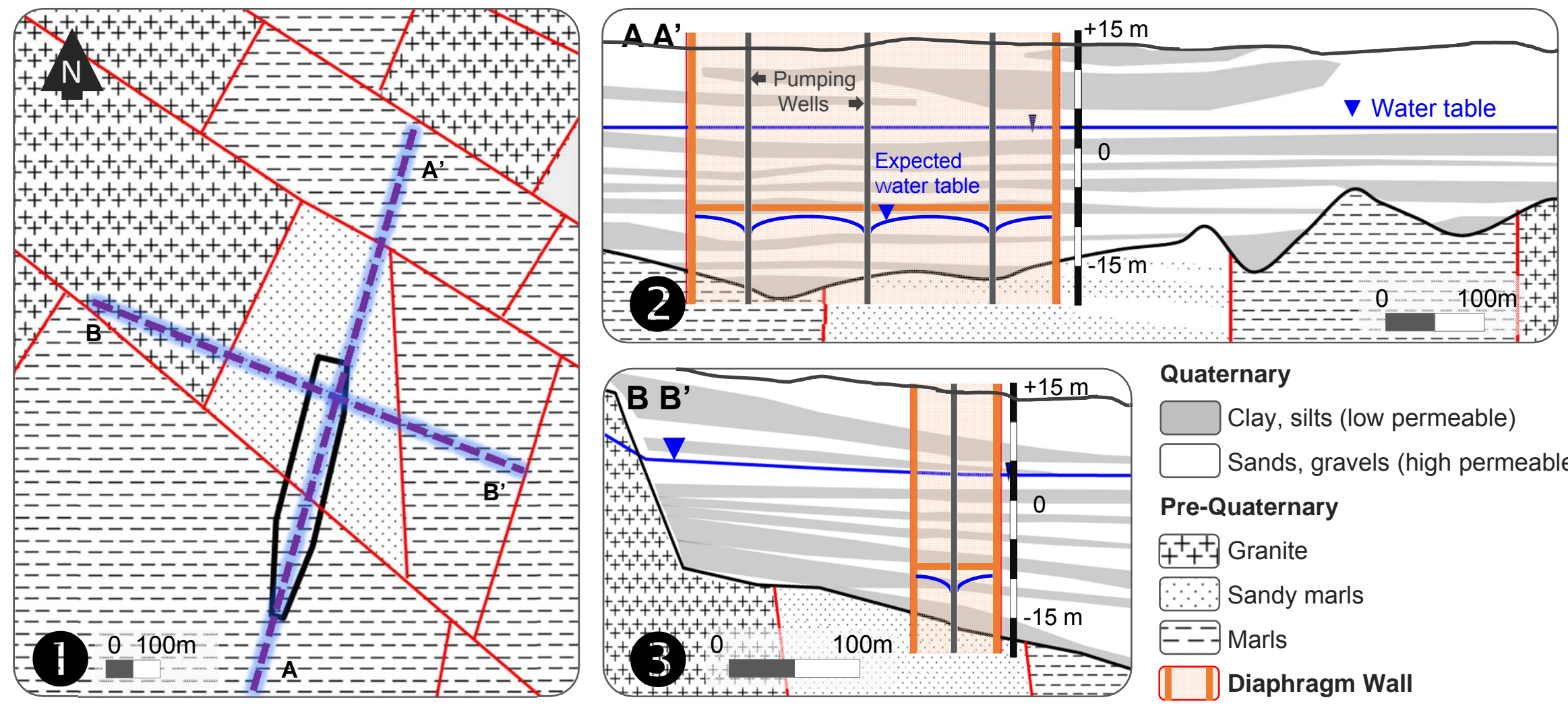

Quaternary

$\square$ Clay, silts (low permeable)

Sands, gravels (high permeable)

Pre-Quaternary

$+++{ }_{+}^{+}$Granite

$\because \because$ Sandy marls

E-OMarls

Diaphragm Wall

_ Faults 
Figure 3.

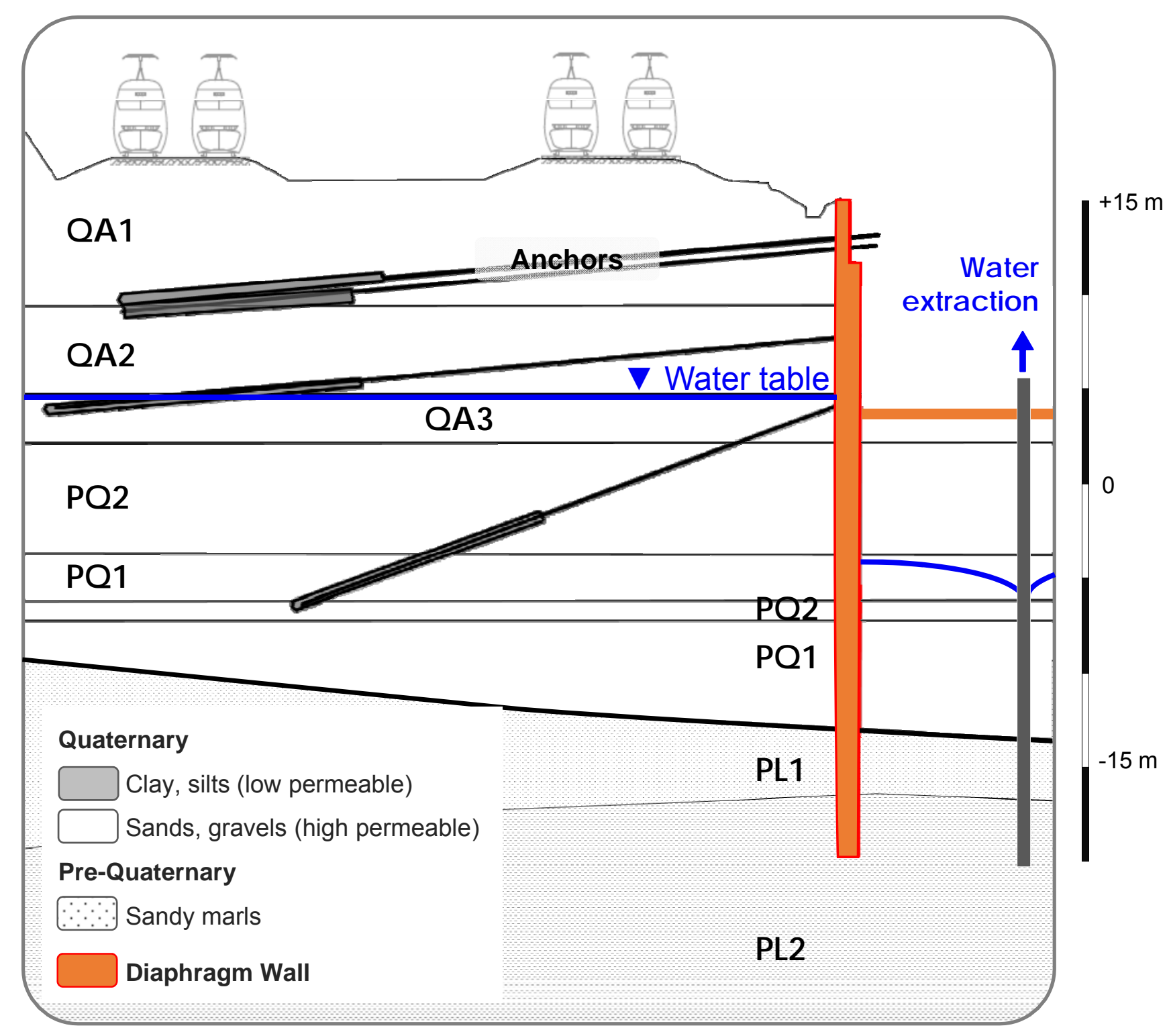


Figure 4.

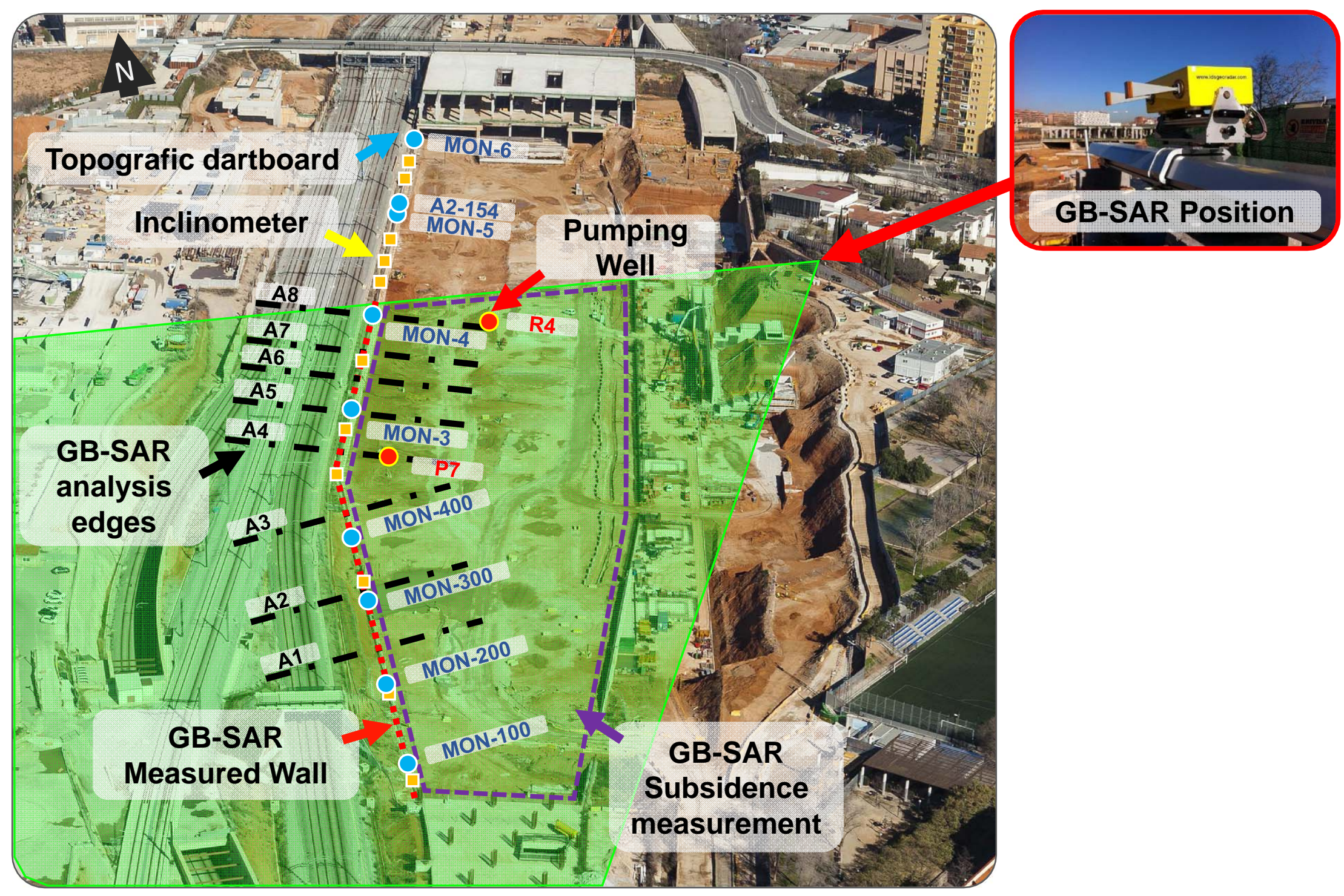




\section{- Figure 5.}

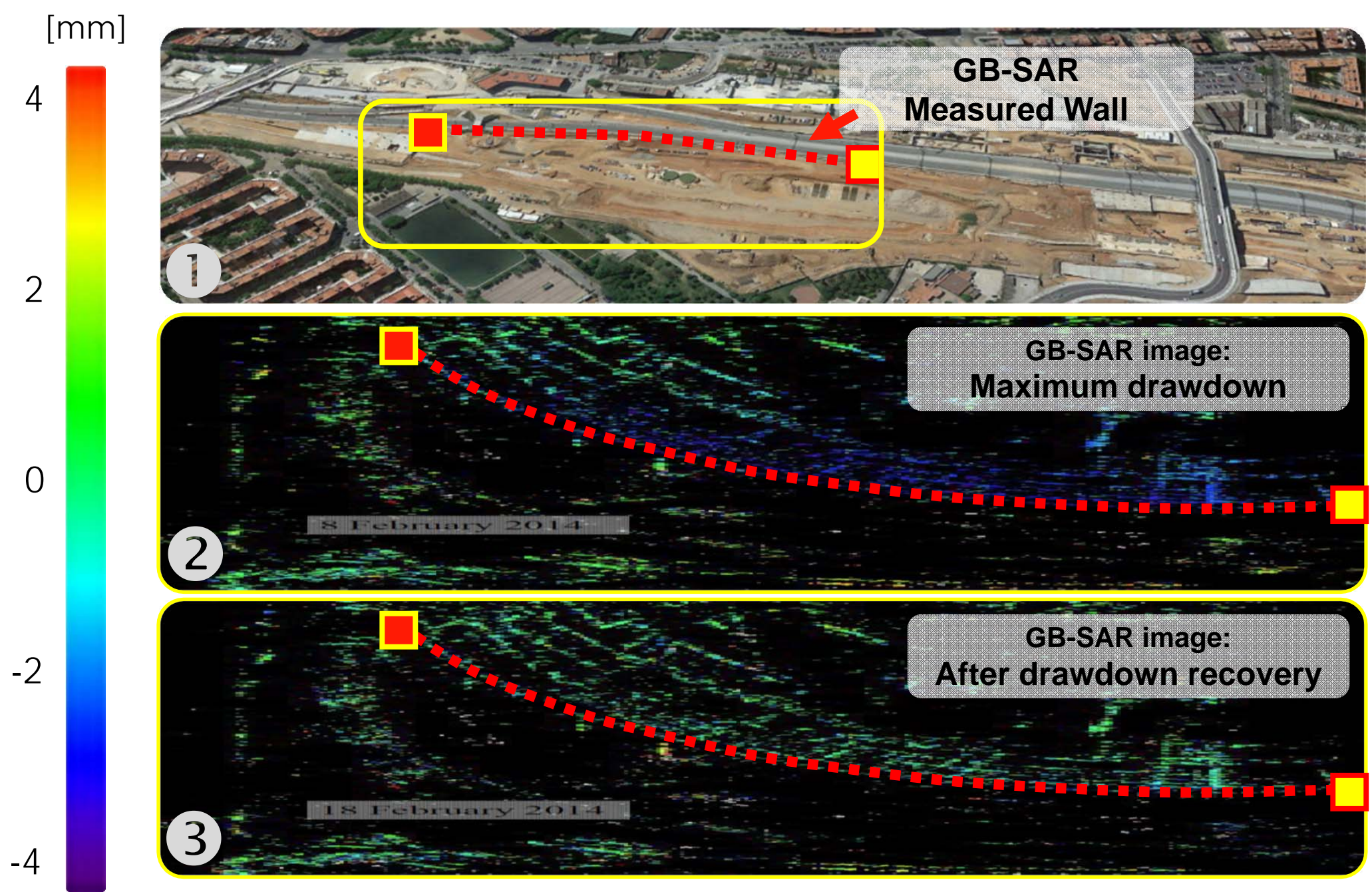




\section{- Figure 6.}

\section{(1)}

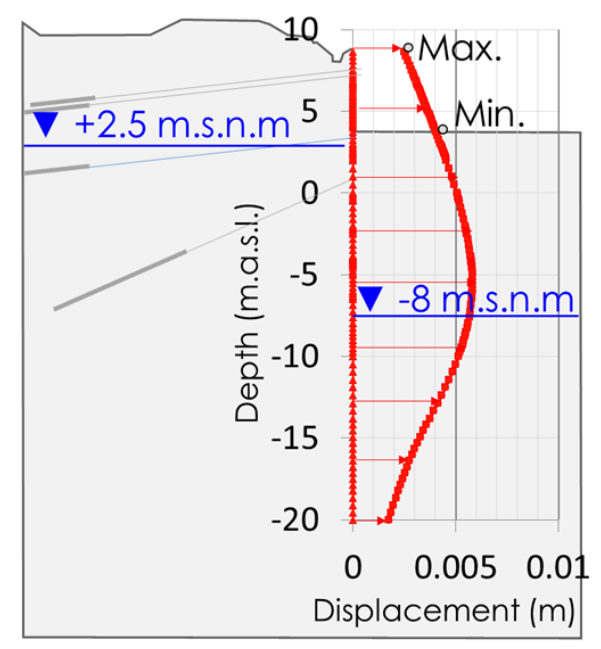

2 Diaphragm wall sections
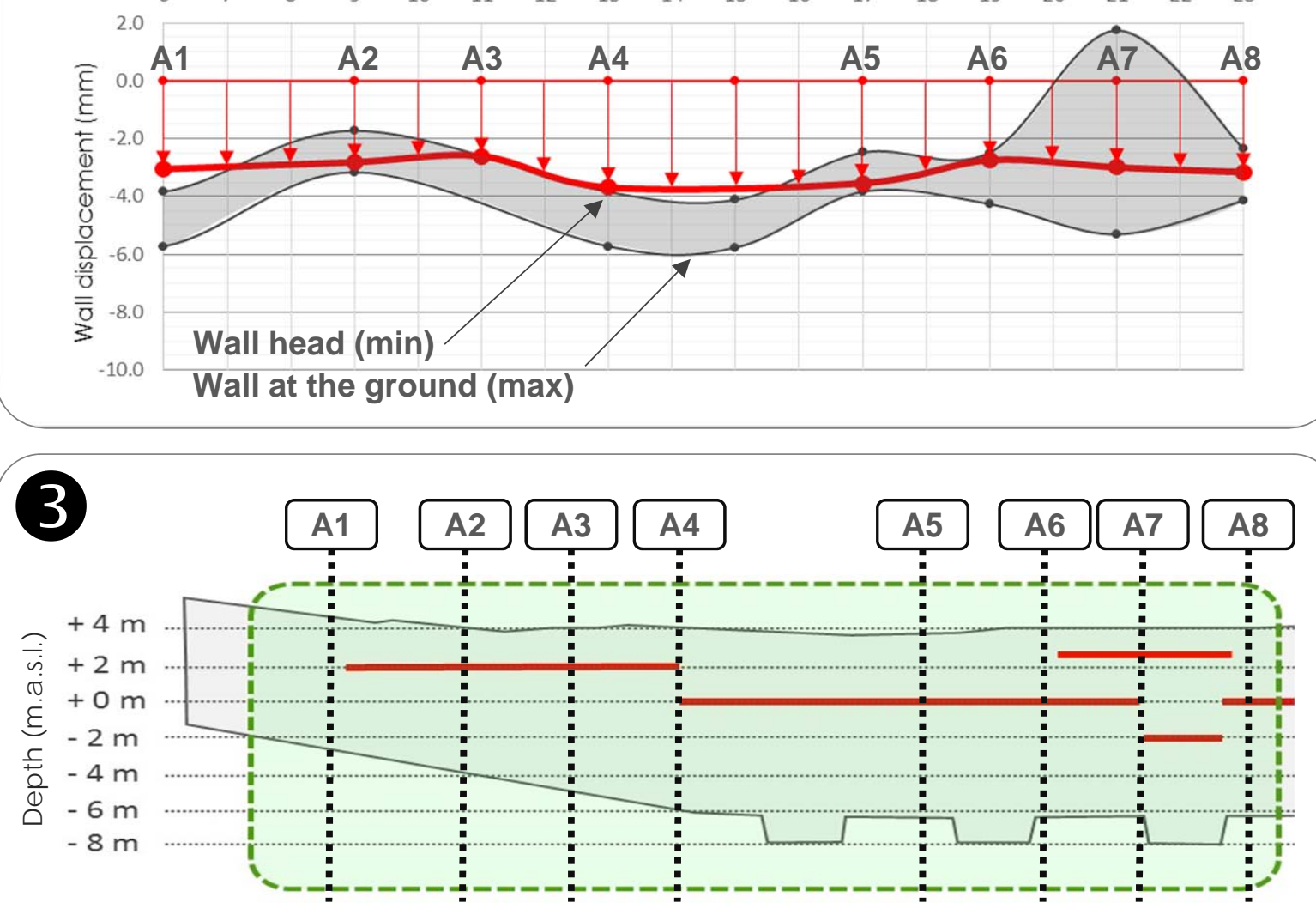
- Figure 7.
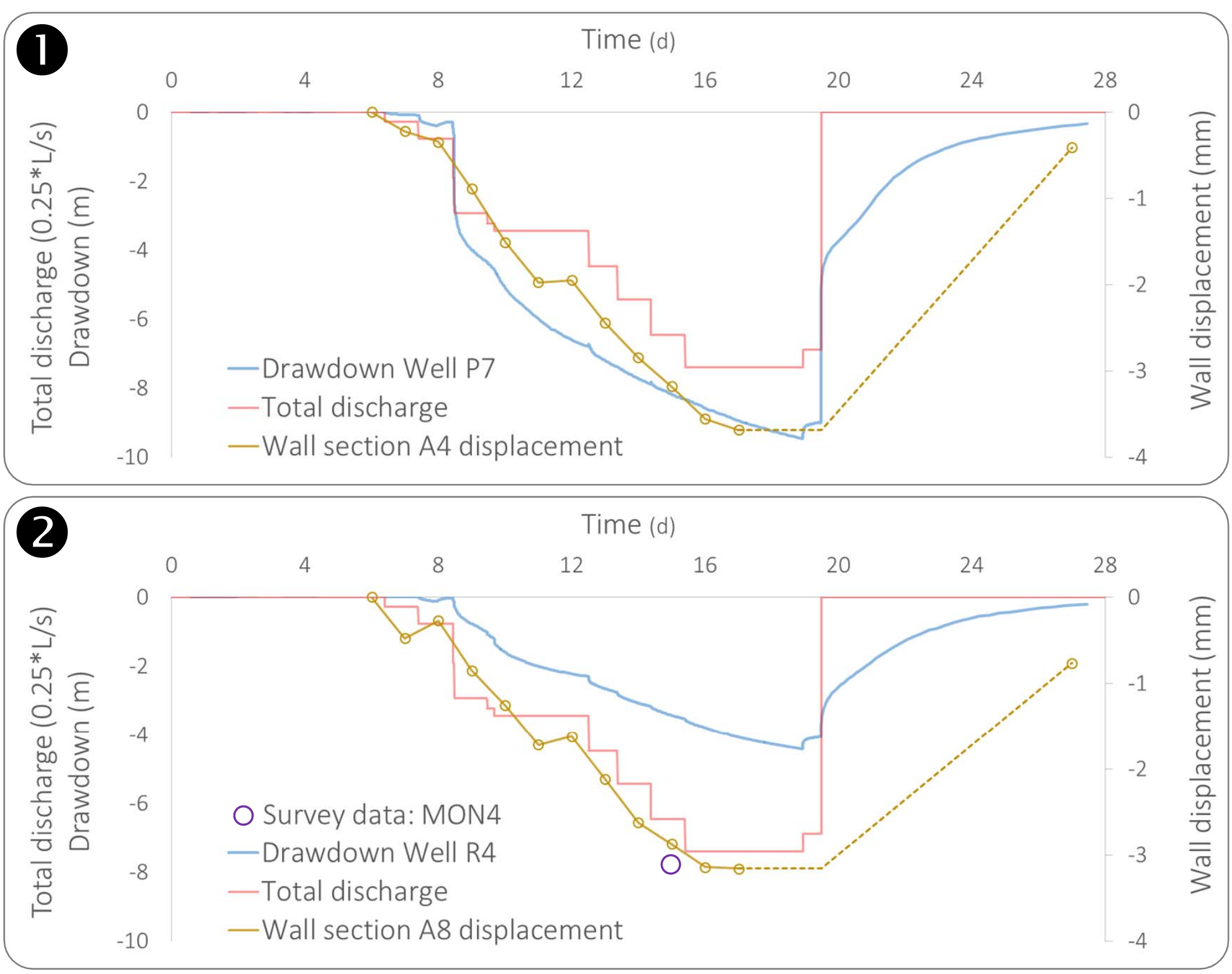
Table 1.

\begin{tabular}{|c|c|c|c|c|c|c|c|c|c|}
\hline \multirow{2}{*}{$\begin{array}{c}\text { LITHOLOGY } \\
\text { GENERAL } \\
\text { DESCRIPTION }\end{array}$} & \multirow{2}{*}{$\begin{array}{c}\text { PALAEOZOIC } \\
\begin{array}{c}\text { GR : Sandy } \\
\text { silt }\end{array}\end{array}$} & \multicolumn{2}{|c|}{ PRE-QUATERNARY } & \multicolumn{5}{|c|}{ QUATERNARY } & \multirow{2}{*}{$\begin{array}{c}\text { ANTHROPIC FILL } \\
\text { RA: fill }\end{array}$} \\
\hline & & $\begin{array}{l}\text { Pa (PI1): Sandy } \\
\text { soil with clay and } \\
\text { silt interlayers }\end{array}$ & $\begin{array}{l}\mathrm{P}(\mathrm{PI} 2): \\
\text { Clay }\end{array}$ & $\begin{array}{l}\text { PQ1: Sand } \\
\text { and gravel }\end{array}$ & $\begin{array}{c}\text { PQ2: Clay } \\
\text { and silt }\end{array}$ & $\begin{array}{l}\text { QA fine: Clay } \\
\text { and silt (Qa1 } \\
\text { y Qa2) }\end{array}$ & $\begin{array}{l}\text { QA granular: } \\
\text { Sand and } \\
\text { gravel (Qa3) }\end{array}$ & $\begin{array}{l}\text { QC: Sandy } \\
\text { gravel with } \\
\text { clay matrix }\end{array}$ & \\
\hline \multicolumn{10}{|c|}{ PARAMETERS } \\
\hline$\gamma t(k N / m 3)$ & 21.0 & 20.5 & 20.5 & 21.0 & 21.0 & 21.0 & 21.5 & 21.5 & 20.0 \\
\hline $\mathrm{C}^{\prime}(\mathrm{kPa})$ & 20.0 & 20.0 & 70.0 & 0.0 & 30.0 & 30.0 & 0.0 & 15.0 & 0.0 \\
\hline$\phi^{\prime}(2)$ & 38.0 & 35.0 & 26.0 & 38.0 & 29.0 & 29.0 & 34.0 & 33.0 & 28.0 \\
\hline $\mathrm{E}(\mathrm{MPa})$ & 50.0 & 40.0 & 40.0 & 25.0 & 20.0 & 20.0 & 18.0 & 18.0 & 10.0 \\
\hline$v$ & 0.3 & 0.3 & 0.3 & 0.4 & 0.3 & 0.3 & 0.4 & 0.4 & 0.4 \\
\hline \multicolumn{10}{|c|}{ Hardening soil model } \\
\hline m & 0.5 & 0.5 & 0.5 & 0.5 & 0.5 & 0.5 & 0.5 & 0.5 & 0.5 \\
\hline $\mathrm{E}_{50}{ }^{\mathrm{rof}}(\mathrm{MPa})$ & 31.0 & 31.0 & 31.0 & 25.0 & 20.0 & 20.0 & 24.0 & 22.0 & 19.0 \\
\hline$E_{\text {oed }} r e f(M P a)$ & 24.8 & 24.8 & 24.8 & 20.0 & 16.0 & 16.0 & 19.2 & 17.6 & 15.2 \\
\hline $\mathrm{E}_{\mathrm{ur}} \mathrm{uf}^{\prime \prime f}(\mathrm{MPa})$ & 93.0 & 93.0 & 93.0 & 75.0 & 60.0 & 60.0 & 72.0 & 66.0 & 57.0 \\
\hline
\end{tabular}

